\title{
Obituary
}

\section{Graeme Harding McDonald}

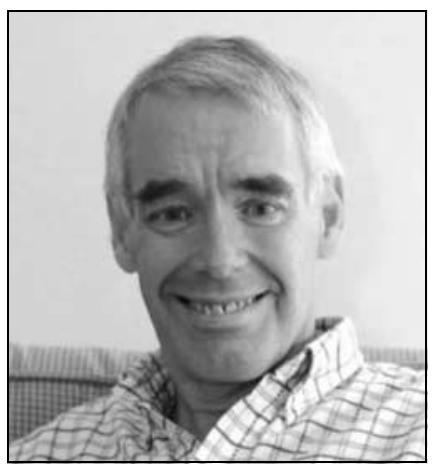

Formerly Consultant Psychiatrist and Associate Medical Director, Belfast

Graeme, born in Belfast on 12 March 1958, was outstanding in every respect. His advice was frequently sought by colleagues both within and outside the psychiatric profession, and he was in

frequent demand as a gifted and stimulating speaker.

Graeme chaired the British Medical Association National Hospital Junior Staff Committee from 1988 until 1990, and was seminal in developing the 'New Deal' programme (he always said that he had really enjoyed being interviewed by Jeremy Paxman!). He was appointed a consultant in 1989 and at the age of 31 was the youngest ever Chair of the Northern Ireland Psychiatric Training Committee. He also served as Regional Advisor and played an active role in every aspect of the Royal College of Psychiatrists' life in Northern Ireland. Furthermore, he was Chair of College Approval Panels for a number of years.

A great strategic thinker, Graeme was appointed Associate Medical Director in the Belfast Health and Social Care Trust in 2007. Always a champion of community-based services, he originated the Belfast Home Treatment Team. Particularly original was his appointment of a service user as a full team member.

He played a major role in the Northern Ireland review of mental health policy and services, the 'Bamford Review'. Graeme was always interested in the broader context of mental health and he was Chair of the Northern Ireland Association for Mental Health. Among his many achievements in this role was his leadership of a major mental health project in Malawi, which has made a real difference to the lives of seriously disadvantaged people. A memorial fund is to be set up to ensure the continuation of this vital work.

Graeme maintained a high level of fitness throughout his life and he enjoyed golf, cycling, running and skiing. He was training for the annual Belfast to Dublin Maracycle until shortly before his illness. He was passionately attached to his family, in whom he took immense pride, and took them all with him whenever he travelled.

In June 2010, Graeme was diagnosed with pancreatic cancer. His humour never deserted him; he dealt with the illness the way he lived: inspiringly. He died on 30 November 2010. He leaves his wife Linda, a GP, whom he met at Queen's University Belfast. Of his children, Jeffrey is an F1 doctor, Kirsty - a medical student, Amy - a psychology student and Zara a sixth-former.

Philip McGarry

doi: 10.1192/pb.bp.111.035253 